\title{
The new EANM paediatric dosage card: additional notes with respect to $\mathrm{F}-18$
}

\author{
M. Lassmann • L. Biassoni • M. Monsieurs • \\ C. Franzius • \\ EANM Dosimetry and Paediatrics Committees
}

Published online: 27 September 2008

(C) Springer-Verlag 2008

\section{Erratum to: Eur J Nucl Med Mol Imaging}

(2008) 35:1666-1668

DOI 10.1007/s00259-008-0799-9

In the original publication the affiliations of the co-author Christiane Franzius were incomplete. Her full affiliations are as given here.

Department of Nuclear Medicine, University Hospital Muenster, Muenster, Germany

MR and PET/CT-Centre Bremen-Mitte, Bremen, Germany

The online version of the original can be found at http://dx.doi.org/ 10.1007/s00259-008-0799-9.

M. Lassmann $(\bowtie)$

Klinik und Poliklinik für Nuklearmedizin

der Universität Würzburg,

Josef-Schneider-Str. 2,

97080 Würzburg, Germany

e-mail: lassmann@nuklearmedizin.uni-wuerzburg.de

L. Biassoni

Department of Radiology,

Great Ormond Street Hospital for Children,

London, UK

M. Monsieurs

Health and Safety Department, Health Physics, Ghent University,

Ghent, Belgium

C. Franzius

Department of Nuclear Medicine, University Hospital Muenster,

Muenster, Germany

C. Franzius

MR-and PET/CT-Centre Bremen-Mitte,

Bremen, Germany

e-mail: christiane.franzius@t-online.de 